\title{
Relationship between EFL Learners' Belief and Learning Strategy Use by English Majors in Vocational Colleges
}

\author{
Fenfang Li \\ School of Foreign Languages, Chongqing Yangtze Normal University, Fuling, Chongqing 408001, China \\ Email: tracy842005@163.com
}

\begin{abstract}
This study, based on two questionnaires, explored relationship between foreign language learning beliefs and the strategy use among English major sophomores of vocational colleges in Jiangxi. In addition, it attempted to find any relationship between the two variables. The results shows: (1) Overall mean of the belief is 3.44, which means majority of subjects agree with the statements or at least stay neutral. They hold strong opinion about the six belief categories, especially about the language learning and communication strategies.(2) The overall strategy use fall within the range of medium use (mean=2.89), which means the vocational students "sometimes" use the strategies. Compensation strategies are the most popular strategies with the vocational English majors, while memory strategies are least used. (3) Moderate correlation coefficient is detected between the language learning beliefs and frequency of strategy use $(r=.476, p<.01)$.
\end{abstract}

Index Terms - beliefs about foreign language learning, language learning strategies, English major students in vocational colleges, correlation study

\section{INTRODUCTION}

Since 1970s, great changes have taken place in the field of Second Language Acquisition research. Interest in EFL has shifted from teacher's teaching to students' learning and a growing number of studies have been undertaken from the learners' perspective. But how can people learn a foreign language more quickly and efficiently? This question has always been the focus of attention of foreign language teachers and researchers. So corresponding to the shift in the field of SLA, researchers have identified such individual learner variables that affect learning outcome as age, aptitude, motivation, cognitive style, learning style, learning belief and learning strategy, etc. Among them, students' learning beliefs about language learning and learning strategy have become heated topics in recent years.

However, there seems to be something that affects the choice of strategies. Influenced by previous experiences as language learners, or shaped by their own cultural backgrounds, second language learners often hold different beliefs or notions about language learning (Horwitz, 1987). Meanwhile, many researchers have suggested that learners' preconceived belief about language learning would likely affect the way they use their learning strategies and learn a second language (Abraham \& Vann, 1987; Horwitz, 1987; Wenden, 1986). Investigation of the relationship between learners' beliefs about language learning and strategy use should provide teachers with better understanding of their students' "expectation of, commitment to success in and satisfaction with their language classes" (Horwitz, 1988, p283).

\section{DEFINITION OF LLB AND LLS}

In the past two decades, the concept of belief has come into the field of ELT (English Language Teaching) and gained much favor among language researchers and practitioners as well. In second language research, learners' beliefs are a term that is often used interchangeably with metacognitive knowledge. Metacognitive knowledge comprises one of three types of knowledge of mankind (the other two are domain knowledge and social knowledge (Wenden, 1999). Generally speaking, there are four characteristics of LLB; Wenden (1991) summarizes them as follows: stable; statable; interactive and fallible.

According to Wenden (1991), language learning belief is the knowledge held by language learner about various factors in language learning process, about how to learn a language, language skills, and communicative competence. Language beliefs are formed either through personal experience or influence from other people.

As to the classifications, Horwitz's classification of learners' language learning beliefs, developed very carefully, encompasses a broad range of language leaning beliefs and subsumed large numbers of more specific foreign language learning beliefs. Horwitz divided language learning beliefs into (1) Foreign language aptitude; (2) Difficulty of language learning; (3) Nature of language learning; (4) Learning and communication strategies; (5) Motivation and Expectations.

L2 learning strategies are specific behaviors or thought processes that student use to enhance their own L2 learning. The word strategy comes from the ancient Greek word strategia, which means steps or actions taken for the purpose of 
winning a war. The warlike meaning of strategia has fortunately fallen away, but the control and goal-directedness remain in the modern version of the word (Oxford, 1990).

Oxford (1990:9) sees the aim of language learning strategies as being oriented towards the development of communicative competence. A general distinction is drawn between direct and indirect strategies, which are further subdivided into 6 groups. The former consist of "strategies that directly involve the target language" in the sense that they "require mental processing of the language."(1990:37), while the latter "provide indirect support for language learning through focusing, planning, evaluating, seeking opportunities, controlling anxiety, increasing cooperation and empathy and other means"(1990:151). The general framework of Oxford's classification was shown in Figure 1:

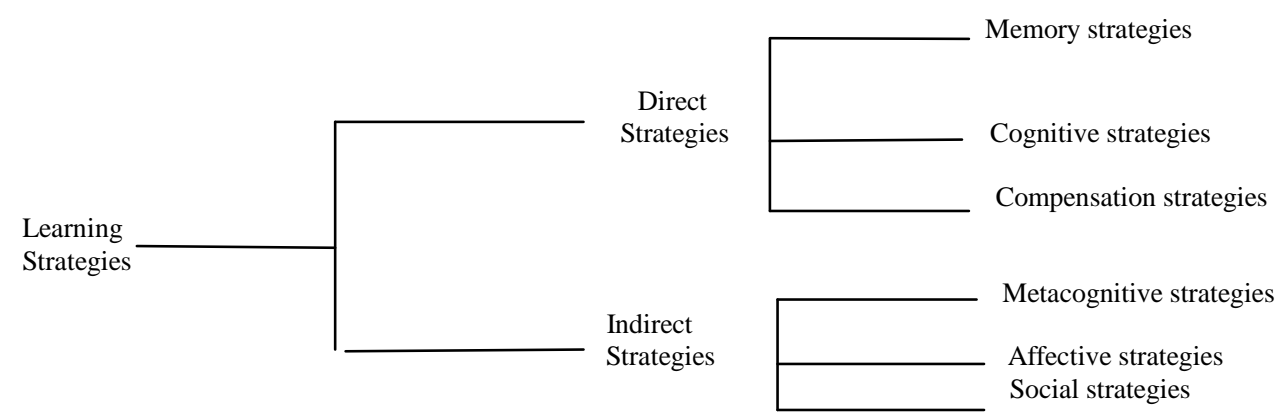

Figure 1 Diagram of a Strategy System: Overview (from Oxford 1990: 16 )

The two high-order classes were subdivided into a total of six groups, with memory, cognitive, and compensation under the direct class; metacognitive, affective, and social under the indirect class. To be more specific;

a. Affective strategies for anxiety reduction, self-encouragement, and self-reward.

b. Social strategies such as asking questions, cooperating with native speakers, and becoming culturally aware.

c. Metacognitive strategies for evaluating one's progress, planning for language tasks, consciously searching for practice opportunities, paying attention, and monitoring errors.

d. Memory-related strategies, such as grouping, imagery, rhyming, moving physically, and reviewing in a structured way.

e. General cognitive strategies, such as reasoning, analyzing, summarizing, and practicing (including but not limited to "active use of the language).

f. Compensatory strategies (to make up for limited knowledge), such as guessing meanings from context and using synonyms and gestures to convey meaning (cited from Green \& Oxford, 1995).

The possible relationship between LLB and LLS was verified in the following studies. Researchers (Abraham and Vann, 1987; Horwitz, 1987, 1988; Wenden, 1986, 1987) have suggested connections between learners' metacognitive knowledge or beliefs about language learning and their choice of language learning strategies.

In 1996, Wen and Wang discussed three kinds of beliefs, three kinds of strategies and the relationship between the two variables. In addition, Wen and Johnson's study (1997) on second language variables and their relationship to English achievements reported that the direct effects of belief variables on strategy variables were strong and consistent, reinforcing the view that teachers and materials writers need to be ware of, and sensitive to students' pre-existing assumptions about the language learning process.

Of the limited studies on the relationship between LLB and LLS at home and abroad, most of whose focus were on the undergraduates in general universities, students in vocational colleges have been always ignored by researchers. This research aimed to see how vocational students' beliefs about English learning are actually related to their learning strategy use.

\section{RESEARCH MethodOLOGY}

\section{A. Research Questions}

The study is designed to answer the following questions: (1) For the entire group, what language learning beliefs and learning strategies are adopted? (2) What is the relationship between learning beliefs and strategy use among the EFL English major sophomores in vocational colleges?

\section{B. Subjects}

In the present study, the subjects were 214 second-year English majors randomly selected from four vocational and technology colleges in Jiangxi. They are Jiangxi College of Foreign Trade, Jiangxi Tourism and Commerce College, Nanchang Institute of Technology and Jiangxi Institute of Technology. Of the 214 respondents, 107 were male and 107 were female. These subjects ranged in age from 19 to 23 .

\section{Instruments}


There were two questionnaires used in the present study. The first questionnaire was "Language Learning Belief Questionnaire" designed by Liu (2003), with a few items chosen from Horwitz's "Beliefs About Language Learning Inventory" (BALLI, EFL version, Horwitz, 1987). The questionnaire has proved effective in investigating Chinese EFL learners' beliefs, which might be adequate in Chinese-associated context. This 50-item questionnaire was constructed encompassing six categories of beliefs. Each item was then incorporated with five-point Likert Scale ranging from strongly disagree to strongly agree. The students were required to respond to each statement from these five scales. Additionally, the questionnaire was conducted in Chinese with a clear layout for a better understanding of the subjects. The 50 belief items were constructed centering around six categories-foreign language aptitude (FLA), the difficulty of language learning (DLL), the nature of language learning (NLL), learning and communication strategies (LCS), learner motivation and expectations (LME), and mother-tongue reliance (MTR).

The second questionnaire was Oxford's (1990) 50-items Strategy Inventory for Language Learning (SILL) (version 7.0), which was used for researching learners about the frequency of their use of 50 common strategies. It has a five-point Likert scale format: learners were asked to report on a scale of one to five how often they use each strategy. The choices are: $1=$ never or almost never; $2=$ usually not; $3=$ somewhat; $4=$ =usually; $5=$ always or almost always. Students were asked to indicate the frequency with which they use a strategy implied in the statement by selecting the number that represents their response. The higher number indicated a more frequent use of the strategy concerned. A Chinese translation of this instrument was also used to maximize ease of administration and ensure greater accuracy of results, especially with the less advanced students.

The structure of SILL is based on Oxford's classification system, whereby strategies are grouped into six categories, each represented by a number of individual strategies (items). Memory strategies(items 1-9); Cognitive strategies (items 10-23); Compensatory strategies (items 24-29); Metacognitive strategies(items 30-38); Affective strategies(items 39-44) and Social strategies(items 45-50)

\section{Data Collection and Analysis}

The questionnaires in Chinese version were distributed to the subjects during regular class hour at the end of their fourth semester with the cooperation of their English teachers in 2008. All the data were collected by the researcher herself at different colleges. The researcher then checked the questionnaires to make sure there were no missing items and each subjects had written down their student numbers.

After collecting the completed questionnaires, all the data were coded and input into the computer, and then analyzed through the Statistical Package for Social Science (SPSS13.0). To be more specific, firstly, descriptive statistics such as frequencies, means, and standard deviations were computed to display the subjects' overall responses to the LLB and strategy items as well as the backgrounds with regard to gender, student number. Secondly, Pearson correlations were conducted to determine the relationships between language learning beliefs and strategy use.

\section{RESULTS AND DisCUSSION}

For the convenience of report, in the part, unless noted, the responses of "strongly agree" and those of "agree" would be put together and reported as responses of "agree". Similarly, the responses of "strongly disagree" and those of "disagree" will be put together and reported as responses of "disagree".

\section{A. Descriptive Statistics of the Primary Variables}

All the 240 questionnaires were collected and returned to the author of the present thesis, 214 of which were valid and used in the following analyses.

a. Language Learning Beliefs

This section reports and presents the general findings according to six categories: foreign language aptitude (FLA, 6 items); the difficulty of language learning (DLL 2 items); the nature of language learning (NLL, 15 items); learning and communication strategies (LCS, 19 items); learner motivation and expectations (LME, 5 items); and mother-tongue reliance (MTR, 3 items). Table 1 presented the overall picture of LLBs about English language leaning.

TABLE1.

\begin{tabular}{|llllllll|}
\multicolumn{10}{c|}{ DESCRIPTIVE STATISTICS OF LLBS } \\
\hline Contents & FLA & DLL & NLL & LCS & LME & MTR & overall \\
Number Valid & 214 & 214 & 214 & 214 & 214 & 214 & 214 \\
Mean & 3.38 & 2.91 & 3.47 & 3.74 & 3.07 & 2.47 & 3.44 \\
Std. Deviation & 0.40 & 0.76 & 0.35 & 0.39 & 0.41 & 0.71 & 0.26 \\
\hline
\end{tabular}

As shown in Table 1, almost all the means of the responses to the six categories were above 3.00 except the beliefs about the difficulty about language learning (Mean=2.91) and mother-tongue reliance (Mean=2.47). Since the participants were asked to respond on a 5-point scale, the above mean scores indicated that most of the participants tended to agree to the statements in the questionnaire except for the beliefs about the difficulty of English and mother-tongue reliance.

b. Language Learning Strategies 
Oxford (1990) suggest a mean of 1.0-2.4 and lower for "low", a mean range of 2.5-3.4 for "medium", and a mean range of 3.5-5.0 for high levels of strategy use. The current study uses the same scale in classifying the participants. Results of the descriptive statistics showed that the mean strategy use by the vocational English majors on the whole strategies was 2.89 , indicating they were medium strategy users.

In other words, the subjects employed strategies in the process of learning English with medium frequency. This finding of the study with respect to the overall mean of strategy use is consistent with the results obtained in other EFL contexts including Yang (1992) in Taiwan and Wharton (2000) in Singapore which all found that EFL learners used strategies at a medium level. However, compared with their undergraduate counterparts in general university studied by $\mathrm{Li}$ (2002), the subjects under investigation in this study indicated lower strategy use. (Mean=2.89 VS mean=2.99), which suggested vocational students uses less strategy than that of general universities. This finding also gave further evidence to the hypothesis that higher proficient learners are better and more frequent strategy users. Table 2 presented the descriptive statistics for strategy categories as used and reported by the participants of the study.

TABLE2.

DESCRIPTIVE STATISTICS OF LLS CATEGORIES EMPLOYED BY VOCATIONAL STUDENTS

\begin{tabular}{|l|l|l|l|}
\hline $\begin{array}{l}\text { Strategy category } \\
\text { (most used to least used) }\end{array}$ & Mean & Standard deviation & Range \\
\hline Compensation & 3.17 & 0.619 & medium \\
\hline Affective & 3.02 & 0.636 & medium \\
\hline Metacognitive & 2.95 & 0.667 & medium \\
\hline Cognitive & 2.92 & 0.579 & medium \\
\hline Social & 2.82 & 0.676 & Low to medium \\
\hline Memory & 2.59 & 0.500 & Low to medium \\
\hline Overall strategy use & 2.89 & 0.470 & medium \\
\hline
\end{tabular}

As it is shown in the above table, the compensation strategies and affective strategies showed comparatively higher mean (3.17 \& 3.02) and other categories fell within a medium to low strategy use level. The next frequently used strategy category was metacognitive and cognitive strategies. The means of the two were relatively the same (2.95 and 2.92 respectively). The mean of social strategies was 2.82 followed by memory strategies with a mean of 2.59 . In other EFL studies, too, compensation strategies were found to be among the most highly frequently used strategies and memory strategies, the least frequently used ones (Yang, 1992). However, the order of rank of the six strategy categories was inconsistent with their counterparts in Li (2002), whose result was similar to that of Oxford. Li's study indicated that the most frequently used strategies were memory strategies, cognitive strategies and metacognitive strategies followed by compensation strategies, and the least frequently used strategies were social and affective strategies.

One possible explanation for the reason why compensation strategies were the most frequently used strategies by vocational English majors might be that high use of compensation strategies usually characterizes the learners who struggle with lower competence. In view of the fact that vocational students are less proficient than their undergraduate counterparts, they have to use compensation strategies whenever they produce or comprehend the target language. In other words, those strategies can make up for the breakdowns during their communication processes. The author found that most of her students used these strategies to make up for their linguistic deficiency. Affective strategies, too, were found to be popular with the vocational students of this study. The findings, nonetheless, contradicted those of studies conducted among undergraduates in general universities, which reported that social and affective strategies were the least frequently used categories. In other words, the high use of affective strategies by vocational English majors might imply that they experienced more affective problems. Indeed, affective strategies enable learners to control their emotions attitudes, and motivations in language learning processes. A likely explanation is that the subjects are less confident than their undergraduate counterparts because of their failure to achieve a rather higher score in the College Entrance Exam. They have to learn to deal with more emotional-related problems, such as anxiety when using English, a language over which they do not have enough mastery.

With respect to metacognitive strategies and cognitive strategies, the results did not show much significant differences with other studies. They were reported to be approximately at the middle of the hierarchy of strategy categories. Metacognitive strategies, like planning, evaluating and monitoring, are very important strategies for the immediate language learners, especially in Chinese context, where language learners do not have much exposure to the target language to pick up the language unconsciously. Through the conscious attention to language learning process, they can compensate for this deficiency.

The last two strategy categories were social and memory strategies. Social strategies mainly concerns interaction with other people, so these strategies were found more popular with ESL learners, who had much more opportunity to use the language or have access to the native speakers than EFL learners.

One surprising finding of the study was that memory strategies were the least frequently used strategies. The results contradict with that of Li (2002), Oxford (1990) and many other studies conducted in Asia, in which Asian learners, 
especially Chinese EFL learners, are stereotypically described as learners who prefer strategies involving rote memorization of language rules.

The low frequency of using memory strategy might be that traditional rote memorization strategies that Chinese EFL learners preferred might differ from the specific memory techniques reported in SILL. These techniques included making a mental picture of the situation in which the word might be used, using thymes to remember new words, and grouping new words into synonyms, antonyms, and nouns. However, the subjects of the study were not familiar with these memory skills listed in the SILL questionnaire. For example, Item 7 "I physically act out new English words" fell within the least frequently strategies. As an English teacher in vocational colleges, the researcher observed that EFL students did memorize language input, such as vocabulary and grammar rules; however, many students used rote memorizing rather than other more useful memory strategies. It is also likely that some memory strategies the students use are not listed on the SILL.

Although students in vocational colleges held strong belief towards memory in language learning, it was disappointing that most of memory strategies they used are rote memory skills rather than meaningful technique which can facilitate their language learning. This also explains why they are less successful learners.

\section{B. Correlation Analysis of Beliefs and Strategy Variables}

In order to investigate the relationship among vocational English majors' beliefs and strategy use, Person correlation procedures were performed on a total of twelve variables: six belief variables and six strategy variables. The belief variables are the underlying factors of the Language Learning Belief Questionnaire found in response to research question one (Language Learning Aptitude, Difficulty of Language Learning Nature, Belief about Strategy, Motivation and Mother-tongue Reliance); the strategy variables are the six strategy categories classified by Oxford.

Table 3 and table4 showed the relationship between language learning beliefs and language learning strategies. The correlation coefficient (represented by " $r$ " in this section) ranges from -1 to +1 . A correlation coefficient whose absolute value is between 0.2 and 0.4 means a low to moderate significant correlation, between 0.4 and 0.7 means a sound significant correlation, between 0.7 and 0.9 means a high significant correlation, below 0.2 means a lowest correlation, which is usually ignored, and above 0.9 means a highest correlation, which scarcely occurs.

Table3 showed the language learning beliefs were significantly and positively correlated with language learning strategies. $(r=.437, \mathrm{p}<.01)$, although the correlation coefficient was not high. In other words, the intensity of LLB that learners hold will greatly influence their use of learning strategies in their English learning. The stronger belief they hold, the more strategies they will use.

TABLE3.

THE TOTAL CORRELATION COEFFICIENT BETWEEN THE LLB AND LLS

\begin{tabular}{|l|l|l|}
\hline \multicolumn{2}{|l|}{ Overall Correlation Coefficient } & $\begin{array}{l}\text { Language learning } \\
\text { strategies }\end{array}$ \\
\hline \multirow{2}{*}{ Language learning beliefs } & $\mathrm{r}$ & $.437 * *$ \\
\cline { 2 - 3 } & $\mathrm{sig}$ & .000 \\
\hline
\end{tabular}

**: Correlation is significant at the 0.01 level (2-tailed)

*: Correlation is significant at the 0.05 level (2-tailed)

TABLE4.

CORRELATION BETWEEN CATEGORIES OF LANGUAGE LEARNING BELIEFS AND LANGUAGE LEARNING STRATEGIES

\begin{tabular}{|c|c|c|c|c|c|c|c|}
\hline \multicolumn{2}{|l|}{$\begin{array}{ll}\text { Beliefs } & \text { Strategy }\end{array}$} & memory & cognitive & Compensation & Metacognitive & Affective & Social \\
\hline \multirow{2}{*}{ Language Aptitude } & $\mathrm{r}$ & .133 & $.271^{* * *}$ & $.180 * *$ & $.223 * *$ & .126 & $.227 * *$ \\
\hline & sig & .052 & .000 & .008 & .001 & .066 & .001 \\
\hline \multirow{2}{*}{$\begin{array}{l}\text { Difficulty of language } \\
\text { learning }\end{array}$} & $\mathrm{r}$ & .125 & $.226 * *$ & .052 & $.171^{*}$ & $.153^{*}$ & .129 \\
\hline & sig & .068 & .001 & .448 & .012 & .025 & .059 \\
\hline \multirow{2}{*}{$\begin{array}{l}\text { Nature of Language } \\
\text { Learning }\end{array}$} & $\mathrm{r}$ & .040 & .066 & .069 & $.171 *$ & $.169 *$ & $.139 *$ \\
\hline & sig & .564 & .336 & .312 & .012 & .014 & .042 \\
\hline \multirow{2}{*}{$\begin{array}{l}\text { Learning and } \\
\text { Communication }\end{array}$} & $\mathrm{r}$ & $.165^{*}$ & $.285^{* * *}$ & $.302 * *$ & $.306 * *$ & $.368^{* * *}$ & $.319 * *$ \\
\hline & sig & .016 & .000 & .000 & .000 & .000 & .000 \\
\hline \multirow{2}{*}{$\begin{array}{l}\text { Learner Motivation and } \\
\text { Expectations }\end{array}$} & $\mathrm{r}$ & $.159 *$ & .129 & .083 & $.224 * *$ & $.156^{*}$ & $.170^{*}$ \\
\hline & sig & .020 & .059 & .228 & .001 & .022 & .013 \\
\hline \multirow{2}{*}{ Mother-tongue Reliance } & $\mathrm{r}$ & -.098 & $-.163 *$ & .008 & -.059 & -.047 & -.100 \\
\hline & sig & .154 & .017 & .912 & .390 & .495 & .144 \\
\hline
\end{tabular}

For the purpose of further study and discussion, table 4 presented the correlation of six factors of language learning belief and six factors of the SILL for the vocational English majors. The six categories of belies and six categories of strategies were significantly correlated with one another with correlation coefficients ranging from -.163 to .368, indicating low to moderate correlations. 
From table 4, we can see Beliefs about Language Aptitude had moderate correlations with four strategies: cognitive strategy $(\mathrm{r}=.271, \mathrm{p}<.01)$; compensation strategy $(\mathrm{r}=.180, \mathrm{p}<.01)$; metacognitive strategy $(\mathrm{r}=.223, \mathrm{p}<.01)$ and social strategy $(\mathrm{r}=.227, \mathrm{p}<.01)$. No significant correlation was found between this belief category and the other two strategies: memory strategy and affective strategy. The results above seemed to suggest that learners who believed in the issue of equal potentiality for language learning, tended to use more cognitive strategy, compensation strategy, metacognitive strategy and social strategy to reach their goals. The Attribution Theory here can be borrowed to explain this result. According to the theory, those who have high expectations for future success in mastering English are usually the ones who attribute their success to stable factors such as innate ability. Hence, it is supposed that the more they believed they had a special ability to learn English, the more likely they would use strategies.

The belief about language difficulty was found to be positively correlated with cognitive strategy $(\mathrm{r}=.226, \mathrm{p}<.01)$; metacognitive strategy $(\mathrm{r}=.171, \mathrm{p}<.05)$ and affective strategy $(\mathrm{r}=.153, \mathrm{p}<.05)$. The result indicated that the subjects' beliefs about relative difficulty of English or their self-efficacy judgments may determine how much effort they would like to make and persist with to learn English when faced with learning difficulties.

In addition, students' belief about Nature of Language Learning showed a weak correlation with metacognitive strategy $(\mathrm{r}=.171, \mathrm{p}<.05)$; affective strategy $(\mathrm{r}=.169, \mathrm{p}<.05)$ and social strategy $(\mathrm{r}=.139, \mathrm{p}<.05)$. In other words, students' beliefs about the nature of language learning might encourage the use of these three strategies. Actually, when students regarded language learning as an important matter they were likely to plan, to organize, to monitor and to evaluate the whole language process by adopting various strategies such as reflection, looking for weak points of their language learning.

It was very encouraging to find that students' beliefs about learning and communication strategies were closely correlated with each strategy categories. Meanwhile, the strongest correlation was found between this belief category and three strategy categories: compensation $(\mathrm{r}=.302, \mathrm{p}<.01)$; metacognitive strategy $(\mathrm{r}=.306$, $\mathrm{p}<.01)$; affective strategy $(\mathrm{r}=.368, \mathrm{p}<.01)$ and social strategy $(\mathrm{r}=.319, \mathrm{p}<.01)$. Hence, those students who held certain beliefs about learning and communication strategies were likely to use all strategies much more frequently than student who did not hold these beliefs. It is rather easy to understand the result when we are reminded that, as mentioned above, this belief category is directly related to the use of strategy.

Beliefs about Motivation and Expectation also had a moderate to weak and positive correlation with memory strategy $(\mathrm{r}=.159, \mathrm{p}<.05)$, metacognitive strategy $(\mathrm{r}=.224, \mathrm{p}<.01)$, affective strategy $(\mathrm{r}=.156, \mathrm{p}<.05)$ and social strategy $(\mathrm{r}=.170$, $\mathrm{p}<.05$ ). The finding suggested that student who were motivated for learning English, instrumentally or integratively, were more likely to use these four strategies than students who were not motivated for learning English. This finding is also consistent with that of Oxford and Nyikos (1989), which found that students' self-reported motivation function as an important determinant of their use of specific types of strategies and overall frequency of strategy use.

Finally, it was shown in the above table that the Belief about mother-tongue reliance was negatively correlated with cognitive strategy $(\mathrm{r}=.-163, \mathrm{p}<.05)$. This suggested that the more reliant students were on their mother-tongue, the less cognitive strategy they will use. As mentioned before, the level of reliance on mother-tongue is negatively associated with proficiency level. The students with low proficiency are more reliant on their mother-tongue, thus ignoring using some other strategies. This result supports Horwitz's (1988) argument that certain students' beliefs would likely restrict the range of language learning strategy used.

The result was consistent with that of Yang (1992), who maintained that there is relationship between college EFL learners beliefs about language learning and their use of learning strategies and found that learners' self-efficacy beliefs about learning English were strongly related to their use of all types of strategies. Also, learners' beliefs about the value and nature of learning English were related to their choice or use of formal oral-practice strategies.

Overall, the correlation between beliefs of vocation English majors about learning and communication strategies and affective strategies was the strongest $(\mathrm{r}=.368, \mathrm{p}<.01)$. The weakest correlation, which was negative, was between beliefs about mother-tongue reliance and cognitive strategy $(\mathrm{r}=.-163, \mathrm{p}<.05)$. In addition, other belief categories had low to moderate correlations with six strategy categories respectively.

The Gap between Students' Beliefs and Actual Strategy Use

A further examination of the results of both LLB and LLS, we may find that there was a significant gap between the students' concept of EFL learning and their actual strategy use. For instance, even though overwhelmingly majority of the subjects approved that learning English involved a lot of memorization, the memory strategy category ranked at the bottom of the list. It was the following items that were most supported by the subjects, item 27 , item 8 , item 19 , item 9 , item 20, and item 32, but their corresponding items in SILL were not the most popular strategies. These indicated that what they think did not mean what they did in real learning situation. For example, as to item $32,83 \%$ of the subjects thought it was necessary to practice pronunciation in order to improve speaking, but its corresponding item in SILL (item 12, I practice the sounds of English) only scored a mean of 3.00, which suggested a medium use. Item 9 (It is necessary to speak English in and out of class in order to improve English proficiency) was another case. More than $90 \%$ of them endorsed the statement, but the item 49 in SILL (I ask questions in English) was one of the least frequently used strategies.

In addition, there were some conflicting cases. Nearly 55\% of the subjects rejected the statement "You should not say anything in English until you can say it correctly", while more than $72 \%$ of them agreed that if beginning students were 
permitted to make errors in English without correction, it would be difficult for them to speak correctly later on. In other words, although the students had a desire to practice English, they were afraid of making mistakes, which would hinder their progress.

However, the author also found that as most students think they felt shy when speaking English, affective strategies like relaxation and self-encouragement were frequently used to overcome their shyness.

This situation was in line with the findings of Yang (1992), who also detected the conflicting beliefs and strategy use. A possible explanation might be that, while the students reported holding some positive and helpful language learning beliefs, the awareness about them was not strong enough. On the other hand, when they found the gap existed between their ideal EEL situation and the actual learning situations in their colleges; they would abandon such belief and eventually, these strategies.

\section{CONCLUSION, IMPLICATIONS AND LIMITATIONS}

\section{A. Conclusion}

The present study has identified language learning beliefs and language learning strategies followed by examining the relationships between language beliefs and strategy use for vocational English majors in Jiangxi with the intention to help the English teachers provide their students with useful suggestions of how to become more proficient EFL learners. Total 214 participants randomly selected from four vocational colleges completed two questionnaires booklet composed of language learning belief questionnaire (Liu, 2003) and SILL (Oxford, 1990, EFL/ESL 7.0). Significant findings were presented in the following.

(1) As to the first question, the results of language learning beliefs were encouraging and cautionary. It was encouraging that most students reported holding a variety of beliefs about learning by the Language Learning Belief Questionnaire. From the descriptive analysis in table 4.1, we can see that overall mean of the belief was 3.44, which meant majority of subjects agreed with the statements or at least stayed neutral.

As to the frequency of strategy used by the entire group, the overall strategy use fell within the range of medium use (mean=2.89), which meant the vocational students "sometimes" use the strategies. The rank of the six strategy categories in the SILL according to the frequency of use was compensation (mean=3.17); affective strategies $($ mean=3.02), metacognitive (mean=2.95), cognitive (mean=2.92) social $(m e a n=2.82)$ and memory strategies $($ mean=2.59). However, the order of rank of the six strategy categories was inconsistent with their counterparts in Li (2002), whose result was similar to that of Oxford. Li's study indicated that the most frequently used strategies are memory strategies, cognitive strategies and metacognitive strategies followed by compensation strategies, and the least frequently used strategies are social and affective strategies.

(2) Correlation Analysis between the language learning belief and the strategy use revealed that LLB was significantly and positively correlated with LLS in general. The moderate correlation coefficient was detected between the LLB and frequency of strategy use. $(\mathrm{r}=.476, \mathrm{p}<.01)$. The result was primarily in line with other studies ( Horwitz, 1987, 1988; Wenden, 1987; Abraham \&Vann; 1987, Yang, 1992; Wen and Johnson,1997). Generally, students who held more positive language learning beliefs were more willing to apply learning strategies, and in turn could acquire better academic performance.

It was also found there was a significant gap between the students' concept of EFL learning and their actual strategy use and conflicting beliefs among the students.

\section{B. Implications}

Displaying and discussing a group of learners' beliefs about language learning and their strategy use is not an end in themselves. The work would be more meaningful and fruitful only when author examines what the findings suggest for teaching similar groups of students. In this section, some theoretical and pedagogical implications will be explored respectively.

From theoretical view, this study explored the relationship between language learning belief and language strategy. The findings of this research further confirmed the argument that students' beliefs about language learning may affect their choice of language learning strategy (Yang, 1992; Horwitz, 1988, 1987; Wenden, 1986, 1987) and the importance of metacognitive knowledge to language learning by providing empirical evidence.

From pedagogical view, some practical implication and recommendation will be given for classroom practice.

1. Identifying and Assessing Students' Language Learning Beliefs and Strategies in the EFL Classroom.

2. Fostering Positive Language Beliefs for Students

3. Conducting Strategy Training Program in Regular Classroom-Strategy Based Instruction (SBI)

4. Implementing Strategies- and Beliefs- Component within the Language Teaching Syllabus

\section{Limitations}

Despite the informing findings, the present study has some limitations.

The first limitation related to small sample size. It should be pointed out that as this study is based on a sample of 214 students in Jiangxi, the generalizations of the results to other populations may be limited. 
The second limitation concerns the methodology in this study. Only quantitative methods were used instead of combination of quantitative and qualitative approaches. Because both quantitative and qualitative methods have their strengths and limitations, both of them are necessary if we are to develop multifaceted insights.

The third one relates to the self-report instruments adopted in this study. As both of LLBQ and SILL are 5-Likert scale questionnaires, it is likely that there is an underlying "regression toward mean" effect in using these two instruments, which might affect their validity. Meanwhile, subjects can only respond to a set of statements and indicate agreement or disagreement by circling an alternative on an answer sheet, as a result, questionnaire can only measure beliefs and strategies in theory and not on actual occasions of talking or writing. There could be some beliefs and strategies used by students were not included in the questionnaire.

On the other hand, the length of the two questionnaires as a whole may have influenced the overall results. The 100-item questionnaires, some students had difficulty and others were tired of filling and choosing the answers.

\section{REFERENCES}

[1] Abraham, R. G., \& Vann, R. J. (1987). Strategies of two language learners: A case study. In A.L. Wenden, A. \& Rubin, J. (Eds.) Learning strategies in language learning. Englewood Cliffs, NJ: Prentice Hall. (p85-102)

[2] Arnold, J (Ed.) (1999). Affect in language learning. Cambridge University Press.

[3] Benson, A. M. F. (1991). Attitudes and motivation towards English: A survey of Japanese freshmen. RELC Journal, 22, 35-45.

[4] Benson, P. \& Lor, W. (1999). Conceptions of language and language learning. System, 27(4), 459-472.

[5] Chamot, A. U., \& O'Malley, J. M. (1994). The CALLA handbook: Implementing the cognitive academic language learning approach. Reading, MA: Addison-Wesley.

[6] Chamot, A.U. \& El-Dinary, P.B. (1999.) Children learning strategies in language immersion classrooms. Modern Language Journal. 83/3, 319-338.

[7] Chamot, A.U. \& Kupper, L. (1989). Learning strategies in foreign language instruction. Foreign Language Annals. 22, 13-124.

[8] Horwitz, E. K. (1985). Using student beliefs about language learning and teaching in the foreign language methods course. Foreign Language Annals 18, 333-340.

[9] Horwitz, E. K. (1987). Surveying student beliefs about language learning. In Wenden, A. \& Rubin, J. (Eds.) Learning strategies in language learning. Englewood Cliffs, NJ: Prentice Hall. (p119-129)

[10] Horwitz, E. K. (1988). The beliefs about language learning of beginning university foreign language students. Modern Language Journal, 72, 283-294.

[11] Horwitz, E. K. (1999). Cultural and situational influences on foreign language learners' beliefs about language learning: A review of BALLI studies. System, 27, 557-576.

[12] Huang, X. \& Van Naerssen, M. (1987). Learning strategies for oral communication. Applied Linguistics, 8 (3), 287-307

[13] Liu Runqing, \&Wu Yi'an. (1993). An Investigation of the Quality of English-Major Graduates. Foreign Language Teaching and Research, No. 1, 36-46 (in Chinese)

[14] Liu Runqing. (1999). Research Methods in English Language Teetering. Beijing: Beijing Foreign Language Teaching and Research Press.

[15] Liu Runqing, \& Dai Manchun. (2003). A Study of EFL Teaching and Development Strategy in China. Beijing: Beijing Foreign Language Teaching and Research Press.

[16] Li Jiongying. (2002). An Empirical Study on Learning Strategies of Chinese ESL Learners. Foreign Language Teaching, No. 1, 42-49 (in Chinese)

[17] Nunan, D. (1999). Second language teaching \& learning. Boston: Heinle \& Heinle Publishers.

[18] Nyikos, M, \& Oxford, R (1993). A factor analytic study of language learning strategy use: Interpretations from information-processing theory and social psychology. Modern Language Journal, 77, 11-21.

[19] Omaggio, A.C. (1978). Successful language learners: What do we know about them? ERIC/CLL News Bulletin, May, 2-3.

[20] O'Malley, J. M., et al. (1985). Learning strategies used by beginning and intermediate ESL students. Language Learning. 35(1), $21-46$

[21] O'Malley, J.M, \& Chamot, A.U (1990). Learning strategies in second language acquisition. Cambridge: Cambridge University Press.

[22] O'Malley, J.M.et.al (1986). The role of learning strategies and cognition in second language acquisition: A study of strategies for listening comprehension used by students of English as a second language. Rosslyn, VA: InterAmerican Research Associates

[23] Oxford, R. (1989). Use of Language Learning Strategies: A Synthesis of Studies with Implications for Strategy Training. System 17. 1-13.

[24] Oxford, R., \& Nyikos, M. (1989). Variables affecting choice of language learning strategies by university students. Modern Language Journal, 73, 291-300.

[25] Oxford, R. (1990). Language learning strategies. New York: Newbury House.

[26] Oxford, R. (1990). Language learning strategies: What every teacher should know. New York: Newbury/Harper Collins.

[27] Oxford, R. L., Ehrman, M. (1993). Second language research on individual difference. Annual Review of Applied Linguistics, $13,188-205$.

[28] Oxford, R. L., Park-Oh, Y., Ito, S., \& Sumrall, M. (1993a). Factors affecting achievement in a satellite delivered Japanese language program. American Journal of Distance Education, 7, 10-25.

[29] Oxford, R. L., Park-Oh, Y., Ito, S., \& Sumrall, M. (1993b). Learning a language by satellite: What influences achievement? System, 21(1), 31-48.

[30] Oxford, R., \& Burry-Stock, J. (1995). Assessing the use of language learning strategies worldwide with the ESL/EFL version of the strategy inventory for language learning (SILL). System, 23, 1-23. 
[31] Rao Zhenhui. (2005). Gender, Academic Major, and Chinese Students: Use of Language Learning Strategies: Social and Educational Perspectives. Journal of Asia TEFL 2/3,115-138.

[32] Wenden, A.L. (1986). What Do Second-Language Learners Know About Their Language Learning? Applied Linguistics. 7:2, 186-205.

[33] Wenden, A. L. (1998). Metacognitive knowledge and language learning. Applied Linguistics, 19, 515-537.

[34] Wenden, A. L. (1991).Learner Strategies for Learner Autonomy. Englewood Cliffs, NJ: Prentice Hall.

[35] Wenden, A. L. (1999a). An introduction to metacognitive knowledge and beliefs in language learning: Beyond the basics. System, 27, 435-441.

[36] Wenden, A. L. (1999b). Learner training in foreign/second language learning: A curricular perspective for the 21st century. (ERIC Reproduction Service No. ED416673).

[37] Wenden, A.L. (2001). Metacognitive knowledge. In Breen, M.P. (Ed.), Learner contributions to language learning. New Directions in Research. Harlow, Essex: Pearson Education Limited. (pp. 44-64)

[38] Wen, Q. F., \& Johnson, R. K. (1997). L2 learner variables and English achievement: A study of tertiary-level English majors in China. Applied Linguistics, 18, 27-48.

[39] Wen Qiufang. (1995). On Differences in English Learning Strategies between Advanced level English Language Learners and Low Level English Language Learners. Foreign Language Teaching and Research, No.3, 61-66

[40] Wen Qiufang. \& Wang Haixiao. (1996a). An analysis of English Learner's Learning Beliefs and Strategies. Journal of PLA University of Foreign Languages, No 4, 61-66 (in Chinese)

[41] Wen Qiufang. (1996b). On English Learning Strategies. Shanghai: Shanghai Foreign Language Teaching and Research Press.

[42] Wen Qiufang. (1996c). The Relationship between English Outcomes and Traditional English Learning Strategies and untraditional Learning Strategies. Modern Foreign Languages, No 10, 39-45 (in Chinese)

[43] Wen Qiufang. (1996d). A Study of Developmental Changes in Language Learning Strategies. Foreign Language Teaching and Research, No 4, 42-48 (in Chinese)

[44] Wen Qiufang. (2001). Developmental Patterns in Motivation, Beliefs and Strategies of English Learners in China. Foreign Language Teaching and Research, No 3, 26-31 (in Chinese)

[45] Wen Qiufang \& Wang Haixiao. (1996). The Relationship of Learner Variables to Scores on College English Test-Band 4. Foreign Language Teaching and Research, No 4, 35-41 (in Chinese)

[46] Yang, N. (1992). Second language learners' beliefs about language learning and their use of learning strategies: A study of college students of English in Taiwan. Unpublished doctoral dissertation. The University of Texas at Austin, Austin, TX.

[47] Yang, N. (1999). The relationship between EFL learners' beliefs and learning strategy use. System, 27, 515-535.

Fenfang Li was born in Jiangxi of People's Republic of China in 1984. She received her MA degree in Teaching Methodology of EFL from Jiangxi Normal University, China in 2008. She is currently an assistant teacher from the School of Foreign Languages, Chongqing Yangtze Normal University, Fuling, Chongqing, People's Republic of China. Her research interests include Second Language Acquisition, theory and practices of Teaching English as a Foreign Language, translation studies and translation teaching. 